\title{
Representações e Processos de Raciocínio na Comparação e Ordenação de Números Racionais numa Abordagem Exploratória
}

\author{
Representations and Reasoning Processes in Comparing and Ordering \\ Rational Numbers in an Exploratory Approach
}

João Pedro da Ponte*

Marisa Quaresma**

\begin{abstract}
Resumo
O presente estudo tem por base uma unidade de ensino de cunho exploratório, em que alunos do $5 .^{\circ}$ ano de escolaridade (de 10-11 anos) trabalham com várias representações dos números racionais, em diferentes significados e tipos de grandeza. Procuramos saber em que medida esta unidade leva os alunos a desenvolver a sua capacidade de comparação e ordenação de números racionais, levando-os a usar diferentes representações e processos de raciocínio informais e formais. A metodologia de investigação é qualitativa e interpretativa, com observação participante das aulas e o estudo de caso de uma aluna. Os resultados mostram que esta aluna desenvolveu a sua compreensão da ordenação e comparação de números racionais, mostrando-se mais proficiente nas representações decimal e em fração. $\mathrm{O}$ estudo sugere que o trabalho com diferentes representações, numa abordagem exploratória, permite que os alunos aprendam a comparar e ordenar números racionais combinando adequadamente processos de raciocínio formais e informais.
\end{abstract}

Palavras-chave:Números Racionais. Representações. Raciocínio. Comparação. Ordenação.

\begin{abstract}
This study is based on a teaching unit that follows an exploratory approach, in which $5^{\text {th }}$ grade pupils $(10-11$ year-old) work with several representations of rational numbers, in different meanings and types of magnitudes. We seek to know if this unit contributes towards the students' development of the capacity of comparing and ordering rational numbers leading them to use different representations and informal and formal reasoning processes. The research methodology is qualitative and interpretative, with participant observation of classes as well as the case study of a student. The results show that this student developed her understanding of sorting and comparing rational numbers, becoming more proficient both in the decimal and in the fraction representation. The study suggests that work with different representations, in an exploratory approach, allows students to learn to compare and sort rational numbers thought adequately combining formal and informal reasoning processes.
\end{abstract}

Keywords: Rational Numbers. Representations. Reasoning. Comparing. Ordering.

* Doutor em Educação Matemática pela Universidade da Georgia (UGA), EUA ). Professor catedrático do Instituto de Educação, Universidade de Lisboa (IEUL), Lisboa, Portugal. Endereço para correspondência: Instituto de Educação, Alameda da Universidade, 1469-013, Lisboa, Portugal. E-mail: jpponte@ie.ul.pt.

** Mestre em Educação (especialidade Didática da Matemática) pela Universidade de Lisboa (UL), Portugal. Professora na Escola Básica José Saramago, Poceirão, Palmela, Portugal e Membro da Unidade de Investigação do Instituto de Educação, Universidade de Lisboa (IEUL), Portugal. Endereço para correspondência: Instituto de Educação, Alameda da Universidade, 1469-013, Lisboa, Portugal. E-mail: mq@ campus.ul.pt. 


\section{Introdução}

Munido das operações de adição e multiplicação, o conjunto dos números racionais constitui um corpo, uma importante estrutura algébrica. Uma das facetas desta estrutura é a existência de uma relação de ordem total: dados dois números racionais $\frac{a}{b} \mathrm{e} \frac{c}{d}$, é sempre possível dizer se são iguais ou se um deles é maior que o outro. A aprendizagem desta relação de ordem constitui um tópico do currículo de Matemática da generalidade dos países, sendo importante para a compreensão dos números racionais e para o estudo posterior dos números reais (nomeadamente dos intervalos em R). Como referem Behr et al. (1992), a compreensão da ordenação e da equivalência de frações é fundamental para a "compreensão do número racional como uma entidade (isto é, um só número) e para a compreensão da grandeza do número" (p. 316).

Este artigo tem por base uma unidade de ensino realizada no $5 .^{\circ}$ ano (alunos de $10-11$ anos), que procurou promover nos alunos a capacidade de resolverem tarefas envolvendo a comparação e ordenação de números racionais. Nesta unidade, os alunos trabalharam em simultâneo as várias representações dos números racionais, em diferentes significados, com diferentes tipos de grandezas, numa abordagem de cunho exploratório (ME, 2007). Isto é, em vez de se ensinarem diretamente procedimentos e algoritmos, mostrando exemplos e propondo exercícios para praticar, valorizou-se a descoberta pelos alunos de estratégias de resolução, usando com flexibilidade diversas representações. Procurou-se, também, levar os alunos a desenvolverem o seu raciocínio, um aspeto fundamental do ensino da Matemática (PONTE; MATA-PEREIRA; HENRIQUES, 2012).

O nosso objetivo é saber em que medida esta abordagem exploratória proporciona o desenvolvimento da capacidade dos alunos compararem e ordenarem números racionais e conhecer o modo como usam diversas representações e como se caraterizam os seus processos de raciocínio. Começamos por situar os conceitos teóricos fundamentais em que nos baseamos (representações e raciocínio) e por passar brevemente em revista as investigações realizadas sobre a comparação e ordenação de números racionais, após o que apresentamos a unidade de ensino e a metodologia de investigação. De seguida, analisamos o desempenho de uma aluna antes, durante e depois da realização da unidade de ensino, com atenção particular ao seu uso de diferentes representações e aos seus processos de raciocínio. 


\section{Comparação e ordenação de números racionais, representações e raciocínio}

O conceito de número racional é multifacetado, envolvendo diversos significados como parte-todo, quociente, medida e operador (CHARALAMBOUS; PITTA-PANTAZI, 2007). Esta variedade de significados, associada ao carácter relacional dos números racionais e à diversidade de representações de um mesmo número racional, faz com que a sua aprendizagem e o seu ensino se tornem um dos mais sérios problemas da Matemática escolar. $\mathrm{Na}$ verdade, as dificuldades de muitos alunos na aprendizagem dos números racionais começam logo nos aspectos mais básicos. Ao dividir o todo em partes, alguns alunos perdem de vista a necessidade de todas as partes serem iguais ou contam as partes incorretamente. Outros, dada uma parte, têm dificuldade em relacioná-la com o todo correspondente. Mesmo quando parecem já ter algum conhecimento dos números racionais, falta-lhes com frequência a compreensão de que os números racionais são números e que podem ser representados de várias formas (POST; BEHR; LESH, 1986). Sistematizando os estudos realizados pelo Rational Number Project, que marcam de forma decisiva o conhecimento sobre a aprendizagem dos números racionais, Post et al. (1985) referem que a comparação e ordenação de frações exigem diversos conhecimentos complexos: (i) a grandeza da fração depende da relação entre os dois números naturais operada pelo símbolo de fração; (ii) existe uma relação inversa entre o número de partes em que o todo está dividido e a grandeza de cada parte; e (iii) quando as frações têm o mesmo denominador há uma relação direta entre o número de partes que se tomam e a grandeza da fração.

As representações desempenham um papel fundamental no trabalho com números racionais. Bruner (1999) distingue as representações ativas (incluindo objetos e movimentos do corpo), icónicas (figuras, esquemas) e simbólicas (dígitos, sinais de operações como + e $\times$ e de relações como = e <). Goldin (2008) e Vergnaud (2009) também salientam a importância de diversos tipos de representações, incluindo materiais manipuláveis, esquemas e sistemas linguísticos e simbólicos. O numeral decimal, a fração, a percentagem, a reta numérica e as linguagens natural e pictórica são diferentes representações do número racional, que os alunos precisam compreender. Post et al. (1993) sugerem que a compreensão dos números racionais está relacionada com a flexibilidade na conversão entre diferentes representações, a flexibilidade nas transformações dentro de cada representação e na independência progressiva de representações pictóricas e de materiais manipuláveis. Estes autores consideram que a reinterpretação de ideias e conceitos requerida pelas conversões leva os alunos a adquirir 
novos conhecimentos e a reforçar os conhecimentos anteriores, alcançando uma compreensão mais ampla e profunda das ideias matemáticas.

A representação em fração origina muitas dificuldades. Lopes (2008) nota que "a notação das frações constitui um obstáculo, não é trivial a associação de uma parte através de dois números inteiros separados por um tracinho" (p. 9). Monteiro e Pinto (2007) indicam que, ao comparar os números $\frac{1}{3} \mathrm{e} \frac{1}{4}$, muitos alunos referem que $\frac{1}{4}$ é maior do que $\frac{1}{3}$ porque 4 é maior que 3. Outros dizem, por exemplo, que $\frac{1}{2}=1,2$, revelando dificuldades na compreensão do sistema de numeração decimal. Estas autoras referem outras dificuldades dos alunos no trabalho com os números decimais, como a confusão entre décimas e centésimas, sem distinguir 2,5 e 2,05. Note-se que a representação verbal também pode trazer dificuldades, uma vez que faz intervir termos que não fazem parte do quotidiano dos alunos.

Geralmente, o ensino começa por usar uma combinação de representações verbais, ativas (objetos) e pictóricas (desenhos ou esquemas) que permitem a ligação entre a interpretação da informação do enunciado e a respetiva solução. Webb, Boswinkel e Dekker (2008) distinguem entre as representações informais, diretamente emergentes do contexto (tempo, dinheiro, parte de uma maçã, etc.), as preformais (como fitas fracionárias e a reta numérica) e as formais (como a fração e o numeral decimal). Defendem que os alunos precisam ser ajudados a apropriar-se de representações preformais como passo preparatório para aprenderem as representações formais.

Entendemos por raciocínio o processo de formular inferências de forma fundamentada. No que respeita ao ensino da Matemática, Lithner (2008) distingue entre raciocínio imitativo e criativo. A nós interessa-nos mais saber se o raciocínio é formal ou informal. Consideramos que os raciocínios realizados podem ser informais se seguem formas de pensar ou de agir próprias do dia a dia ou formais quando atendem à definição dos objetos matemáticos envolvidos, às propriedades desses objetos, às convenções matemáticas ou a procedimentos matemáticos já anteriormente aprendidos. Na resolução de problemas envolvendo números racionais os alunos têm de pôr em prática processos de raciocínio que, em muitos casos, combinam aspetos formais e informais.

Note-se que o raciocínio formal segue regras e procedimentos matemáticos já conhecidos, mas pode ser realizado em duas condições: de modo mecânico, por simples execução dos passos memorizados, ou com compreensão da razão de ser desses passos e do procedimento geral que se está a seguir (Figura 1). Esta compreensão tem por base analogias e conexões com situações bem conhecidas, sejam situações matemáticas ou do dia a dia do 
aluno. Note-se que tanto o raciocínio informal como o formal pode ser matematicamente correto ou incorreto. Gravemeijer (2005) considera que o grande problema do ensino da Matemática é saber como promover a articulação progressiva entre os processos de raciocínio informais e formais, sustentando que a valorização de processos de raciocínio informais ajuda a encurtar o fosso entre o conhecimento pessoal informal dos alunos e o seu conhecimento formal em desenvolvimento. A nossa perspectiva é que o raciocínio formal com compreensão se desenvolve num processo de vaivém sobretudo a partir do raciocínio informal.

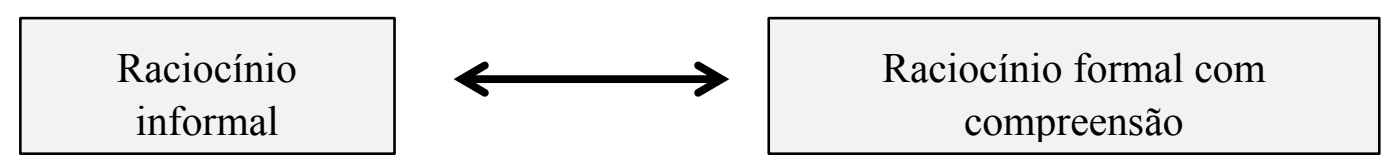

Raciocínio formal sem compreensão

Figura 1 - Raciocínio informal e formal com e sem compreensão

As investigações de Post, Behr e Lesh (1986) mostraram que os alunos usam processos de raciocínio informais na resolução de tarefas de comparação de frações. Um deles é o raciocínio residual que se refere à quantidade que é necessária para construir o todo. Assim, na comparação entre $\frac{5}{6} \mathrm{e} \frac{7}{8}$, os alunos percebem que no primeiro caso falta $\frac{1}{6}$ para completar o todo (o valor residual) enquanto no segundo só falta $\frac{1}{8}$ e concluem então que $\frac{7}{8}>\frac{5}{6}$. Outro raciocínio tem por base a utilização de pontos de referência, que envolve a comparação de duas frações utilizando uma terceira como referência, frequentemente $\frac{1}{2}$ ou 1 . Por exemplo, um aluno diz que $\frac{5}{8}$ é maior do que $\frac{3}{7}$, porque a primeira fração é maior e a segunda é menor do que metade. Outro processo, ainda, é o raciocínio diferencial. Alguns alunos afirmam que $\frac{5}{6}$ e $\frac{7}{8}$ são equivalentes, porque lhes falta apenas uma parte para formar o todo. Neste caso trata-se de um raciocínio incorreto que leva o aluno a focar-se na diferença entre 5 e 6 e entre 7 e 8 , sem considerar a grandeza real da fração, o que é uma forma característica de pensar quando se trabalha com números naturais.

O procedimento usual indicado no currículo escolar para comparar duas frações é procurar frações equivalentes com denominadores comuns. Por exemplo, para comparar $\frac{2}{5} \mathrm{e} \frac{7}{18}$ pode-se encontrar frações equivalentes às dadas com denominador $90, \frac{36}{90} \mathrm{e} \frac{35}{90}$, que mostra que 
$\frac{2}{5}$ é maior. Contudo, como indicam Orton et al. (1995), este procedimento, geralmente, não é muito significativo para os alunos do 5. ${ }^{\circ}$ ano. Pelo seu lado, Bezuk e Cramer (1989) indicam que um procedimento possível para comparar e ordenar números racionais é escrevê-los na representação de numeral decimal à qual se pode associar a representação na reta numérica.

\section{Metodologia}

\subsection{Unidade de ensino}

Este trabalho tem por base uma unidade de ensino concebida a partir da conjetura geral de ensino-aprendizagem (COBB; CONFREY; DISESSA; LEHRER; SCHAUBE, 2003) segundo a qual os alunos desenvolvem a sua compreensão e o seu sentido de número racional ao trabalharem simultaneamente as várias representações, nos diferentes significados e com diferentes tipos de grandezas numa abordagem exploratória. Consideramos como representações formais as que correspondem a sistemas simbólicos com regras convencionais bem definidas (numeral decimal, fração e percentagem) e consideramos como representações informais as que se usam em contextos do dia a dia (ativa e pictórica).

Antes da planificação da unidade de ensino realizamos uma aula de diagnóstico de 90 minutos focada nos conhecimentos dos alunos sobre números racionais. Nesta aula foram propostas tarefas sobre a noção, ordenação e comparação de números racionais e equivalência de frações, em diferentes representações. Os alunos, que apenas tinham estudado estas noções na forma decimal e no significado operador, mostraram dificuldade na linguagem própria das frações, dizendo por exemplo segunda parte para se referirem a um meio, ou terceira parte para se referirem a um terço, e evidenciaram algumas dificuldades na compreensão de numerais decimais. Contudo, mostraram ser capazes de usar frações unitárias como operadores, apoiando-se na ideia de divisão (o divisor é o denominador da fração unitária). Assim, consideramos prioritário trabalhar aspectos do sistema de numeração decimal e da ordenação dos numerais decimais, como base para uma compreensão mais sólida e completa das novas noções a estudar.

$\mathrm{Na}$ unidade começamos por introduzir as diferentes representações de número racional, evidenciando as relações existentes entre elas, bem como as respectivas conversões. De seguida, propusemos tarefas na representação decimal nos diversos significados, envolvendo comparação e ordenação. Posteriormente, introduzimos frações impróprias, 
numerais mistos fracionários e percentagens, como novas formas de representação, utilizando representações pictóricas como apoio para que os alunos visualizassem as transformações realizadas. Estes eram estimulados a escolher a representação que mais se adequava ao contexto do problema ou pela qual tinham preferência. Propusemos então tarefas envolvendo partilha equitativa, retomando os conceitos de comparação e ordenação de números racionais estudados no $1 .^{\circ}$ ciclo na representação decimal, agora envolvendo também a representação em fração. A comparação de frações foi introduzida começando por pares de frações com numeradores iguais ou com denominadores iguais. Pelo seu lado, a ordenação foi realizada em situações envolvendo números representados em fração, decimal e percentagem, começando por frações simples que os alunos facilmente relacionavam com as outras representações. Neste quadro, foi aceito como legítimo o procedimento para comparar números racionais em diferentes representações ou dados por frações com diferentes denominadores (e numeradores) proposto por alguns alunos de converter todos os números dados na representação decimal. Para sustentar os procedimentos de ordenação e comparação de números racionais, foi introduzida a reta numérica. Todas as tarefas propostas na unidade de ensino tinham uma característica comum - usar representações e significados diferentes, para que os alunos adquirissem flexibilidade nas conversões e trabalhassem de forma integrada os diversos significados de número racional. Além disso, propusemos tarefas de natureza diversa, incluindo problemas e explorações, isto é, tarefas de natureza "instigante" (LOPES, 2008), e também exercícios.

$\mathrm{Na}$ aula, a realização das tarefas envolve três fases: (i) a apresentação da tarefa e a sua interpretação pelos alunos; (ii) a realização da tarefa pelos alunos; e (iii) a discussão/reflexão final (PONTE; OLIVEIRA; CUNHA; SEGURADO, 1998). Na exploração das tarefas predomina o trabalho em pares. Procuramos que os momentos de discussão coletiva constituam, oportunidades para negociação de significados matemáticos e construção de novo conhecimento (PONTE, 2005). Valorizamos os processos de raciocínio informais dos alunos, bem como os seus conhecimentos anteriores. Assim, privilegiamos os processos de raciocínio informais e as representações que eles já conheciam para, a partir dai, introduzirmos gradualmente as novas representações de número racional. A introdução de novas representações não implica deixar de usar as anteriores, mas sim desenvolver flexibilidade para escolher a representação mais eficaz em cada contexto ou situação problemática. Procuramos que os problemas propostos envolvam, tanto quanto possível, contextos significativos para os alunos (GRAVEMEIJER, 2005). O objetivo não é estimular os alunos a 
usar exclusivamente estratégias informais, mas sim que fiquem a conhecer e a saber usar os procedimentos formais (matematicamente os mais eficazes) com compreensão.

\subsection{Metodologia de investigação}

Esta investigação tem uma natureza qualitativa e interpretativa (BOGDAN; BIKLEN, 1994). Trata-se de uma investigação que incide sobre a prática profissional da segunda autora, que assumiu simultaneamente os papéis de professora e investigadora. Apresentamos o caso de Leonor, uma aluna com bom desempenho em Matemática, que usa diversas estratégias na resolução de problemas e tem boa capacidade de comunicação oral e escrita. Revela também bom desempenho no cálculo mental, usando com destreza as propriedades das operações e relações entre números. A aluna é muito participativa na aula, gosta de novos desafios e mostrou-se entusiasmada com o estudo dos números racionais. Por tudo isto, é uma aluna cujo desempenho nos pareceu interessante estudar.

Foram realizadas duas entrevistas com Leonor envolvendo tarefas matemáticas, uma antes e outra depois da unidade de ensino, tendo em vista conhecer a sua capacidade para lidar com o conceito de número racional e trabalhar com números racionais nas suas múltiplas representações. Pretendemos, também, compreender os seus processos de raciocínio na resolução de problemas. As entrevistas foram registadas em vídeo e áudio, sendo recolhidos e analisados os trabalhos escritos que realizou nas diversas tarefas.

A análise de dados assume um carácter descritivo e interpretativo. Procedemos à transcrição integral das gravações das entrevistas, usando na análise um sistema de categorias organizado em dois grandes temas: (i) utilização de várias representações de número racional (decimal, pictórica, fração e percentagem) e (ii) processos de raciocínio usados na comparação e ordenação de números racionais. Procuramos ver como usa as representações verbais, ativas e pictóricas e as representações em numeral decimal, percentagem e fração. Leonor tem familiaridade com todas estas representações, exceto a fração, só conhecendo bem as frações unitárias. Dizemos que usa processos de raciocínio informais quando segue formas de pensar ou procedimentos comuns do dia a dia e usa processos de raciocínio formais quando atende sobretudo à definição dos objetos matemáticos envolvidos, a propriedades desses objetos ou a procedimentos formais conhecidos. 


\section{Comparação e ordenação de números racionais antes da unidade de ensino}

Começamos por mostrar como Leonor lida com questões de comparação e ordenação de números racionais numa tarefa na entrevista realizada antes da unidade de ensino.

Tarefa. Ordene os seguintes números por ordem crescente:

a) 0,$5 ; 2,29 ; 0,45 ; 5,02 ; 2,200$

b) $\frac{1}{2} ; \frac{7}{8} ; \frac{3}{4}$

Quadro 1 - Tarefa 1 da entrevista inicial

Esta tarefa, em contexto puramente matemático, envolve a ordenação de números racionais nas representações decimal e fracionária. $\mathrm{Na}$ questão a), Leonor compara corretamente os dois números mais pequenos, 0,45 e 0,5 , recorrendo ao procedimento formal de acrescentar zeros nos dois casos para ter o mesmo número de casas decimais:

Leonor: O maior... É crescente... O mais pequeno... É o 0,45.

Professora: Porquê?

Leonor: Porque se nós acrescentarmos mais um zero, fica 0,450 e este não (este) fica

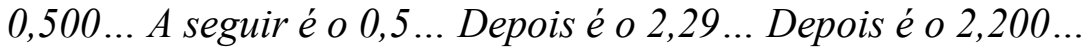

(Entrevista inicial)

No entanto, logo de seguida Leonor erra na ordenação dos números 2,29 e 2,200. Começa por dizer que 2,200 é maior, sem ter em atenção os algarismos das centésimas que surgem em 2,200 e 2,29. Mas quando a professora lhe pede que explique como está a pensar, recorre ao mesmo procedimento formal, mas não nota o seu erro. Só perante a insistência da professora corrige a sua resposta:

Leonor: Depois é o 2,29... Depois é o 2,200...

Professora: Por quê?

Leonor: Porque aqui já estão os 2 zeros e aqui se acrescentar um zero aqui fica 290 e aqui está só 200.

Professora: Então qual é o maior desses dois números?

Leonor: O maior destes dois números é este (2,29), não é este (2,200)... Tenho que trocar isto!

(Entrevista inicial)

Esta questão coloca em jogo procedimentos formais já muito bem interiorizados (ordenação de números inteiros por contagem simples) e procedimentos formais bem mais sofisticados (ordenação de números na forma decimal, tendo em atenção os valores 
posicionais pertinentes). Vê-se que Leonor aprendeu anteriormente (no $1 .^{\circ}$ ciclo) o procedimento formal correto para resolver a questão proposta na representação decimal (acrescentar zeros para ficar com o mesmo número de casas decimais, de modo a poder comparar facilmente dois números). Usa o procedimento corretamente quando tem que comparar um número com uma casa decimal com outro número com duas casas decimais, mas não o usa quando tem de comparar um número com duas casas decimais e outro com três casas, situação em que segue o raciocínio informal próprio dos números inteiros. Este erro pode ter acontecido por se tratar de números com mais casas decimais (e portanto mais complexos) ou apenas por distração. A aluna parece conhecer o procedimento correto, mas não ser capaz de identificar as situações em que este deve ser aplicado. $O$ fato de ter de explicar como pensou leva a aluna a tornar o procedimento mais explícito, mas mesmo assim só identifica o seu erro perante uma nova pergunta da professora que sugere implicitamente que a resposta estava errada.

A questão b) revela-se um problema difícil para a aluna dada a sua reduzida familiaridade com as frações. No $1 .^{\circ}$ ciclo, Leonor apenas trabalhou com frações como operadores. Conhece, por isso, as frações unitárias e sabe que $\frac{1}{2}$ é metade e $\frac{1}{3}$ é a terça parte. Mas não consegue fazer uma leitura verbal correta de frações não unitárias. Nesta questão afirma que a maior fração é $\frac{1}{2}$ porque se fosse, por exemplo, um bolo isso significava que comeria a metade e, segundo ela, metade “é muito". Em contrapartida, considera que $\frac{7}{8}$ não é tanto porque está “partido" em 8 partes. Ou seja, dá atenção ao tamanho de cada fatia e não tem em conta a quantidade de fatias que se tomam:

Leonor: E agora tenho de pôr em [ordem] crescente estas, não é?

Professora: Sim. Essas quê?

Leonor: As frações.

Professora: Qual é que é o mais pequenino?

Leonor: É o 7 por 8.

Professora: Porquê?

Leonor: Porque aqui no 1 por 2, só temos 2 é a metade e aqui temos a quarta parte e aqui temos a oitava parte... Temos a sétima parte só temos que dividir... Por 8 , são 8 fatias e ele só come 7.

Professora: Só?

Leonor: Sim, e come menos. Muito menos do que se comesse 1 de 2.

Professora: Muito menos?

Leonor: Sim. 
(Entrevista inicial)

Neste caso, para raciocinar sobre o problema, Leonor sente necessidade de recorrer a uma situação contextualizada que conhece bem - um bolo dividido em fatias. Começa por considerar que $\frac{1}{2}$ é maior porque é uma fatia grande, enquanto aquilo que chama a "oitava parte” é mais pequeno. Percebe-se que compara apenas a fração unitária em cada situação e não toma em consideração o numerador, ou seja, o número de partes que se toma do todo. Deste modo, mostra não ter ainda aprendido a noção de fração como relação entre duas quantidades, focando-se apenas numa delas, neste caso o número de partes do todo (representadas no denominador). Ou seja, toma todas as frações como unitárias. O raciocínio de Leonor não atende à definição de fração, mas sim a outro objeto mais simples, a fração unitária, com o qual ela usa um raciocínio informal - quando dividimos um bolo em partes iguais, quantas mais partes temos, mais pequenas estas são.

Para ajudar Leonor a ultrapassar a dificuldade, a professora sugere-lhe que represente cada uma das frações dadas numa imagem e esta toma a iniciativa de desenhar círculos e dividi-los em 2, 8 e 4 partes iguais (Figura 2):

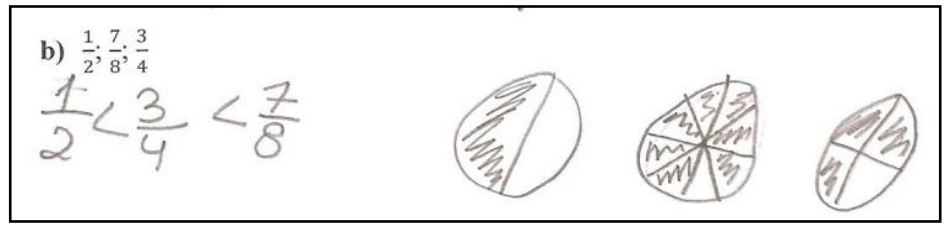

Figura 2 - Resposta de Leonor à questão 1 b da entrevista inicial

Professora: Olhando agora para as imagens vê lá onde é que tu achas que se come menos e ordena.

Leonor: Aqui come 7 fatias do bolo, aqui come uma que é a metade do bolo e aqui come a terça parte do bolo.

Professora: A terça parte?

Leonor: A quarta...

Professora: Quantas quartas partes?

Leonor: Três quartas partes.

Professora: Então agora ordena lá as imagens. Neste caso ordenas as frações olhando para as imagens. Qual é que tu achas que é a mais pequenina? Em qual é que tu achas que comes menos?

Leonor: Em um por dois ... E a seguir é 3 por 4 ... E depois o 7 por 8.

Professora: Então? Mudámos de perspetiva? Aquele que era o mais pequenino passou a ser o maior?

Leonor: Sim, porque come 7 ...

(Entrevista inicial) 
Neste caso, a mudança da representação em fração para a representação pictórica (uma forma de representação icónica) ajuda, claramente, Leonor na ordenação das frações. Esta discussão mostra-se produtiva, pois, conjugando as representações pictórica e em fração, a aluna tem a possibilidade de verificar a vantagem em, por vezes, converter uma representação formal noutra mais informal.

Neste ponto do seu percurso de aprendizagem, Leonor ainda não conhece suficientemente bem a noção de fração de modo a poder fazer a comparação pedida usando apenas esta representação. Só lhe restava portanto a hipótese de transformar as frações dadas noutra representação, como a decimal ou a pictórica, o que fez com desembaraço, mostrando que o uso de representações informais pode ajudar a desenvolver a compreensão de representações formais.

\section{Comparação e ordenação de racionais durante a unidade de ensino}

Em seguida, apresentamos alguns momentos de trabalho da turma durante a unidade de ensino, sobre questões relativas à comparação e à ordenação de números racionais, em que Leonor participa ativamente.

Tarefa. Partilhando pizzas.

Questão 1. Quatro amigos foram a um restaurante e pediram três pizzas. Dividiram igualmente as três pizzas. Que parte da pizza comeu cada amigo?

Questão 2. Se em vez de quatro amigos, fossem oito amigos, pedissem três pizzas e as dividissem igualmente, que parte de pizza comeria cada um?

Questão 3. Em qual dos grupos anteriores, o de quatro amigos (Questão 1) ou o de oito amigos (Questão 2), cada amigo comeu mais pizza? Explica o teu raciocínio.

Quadro 2 - Tarefa 1. Ficha de trabalho 4 (Tarefa adaptada de MONTEIRO; PINTO, 2007)

Questão 1. Esta questão é uma situação contextualizada e envolve o significado quociente e grandezas contínuas. É pedido aos alunos que partilhem equitativamente 3 pizzas por 4 amigos. A informação é dada verbalmente e não é especificada a representação a utilizar nas respostas.

A tarefa apresenta um contexto familiar para os alunos, o que faz com que estes se mostrem muito entusiasmados na sua realização e tentem fazer explicações o mais completas possível das suas resoluções. Inicialmente, usam apenas representações simbólicas mas apresentam alguma dificuldade na realização da tarefa, pelo que a professora dá a sugestão que usem outra forma de representar o problema. Assim, os alunos desenham 3 pizzas, mas 
alguns não conseguem repartir as pizzas pelos 4 amigos. Nessa altura, a professora sugerelhes que atribuam nomes às fatias (como na Figura 3). Com isso, utilizando essencialmente a representação pictórica, a maioria dos alunos consegue partilhar as 3 pizzas pelos 4 amigos.

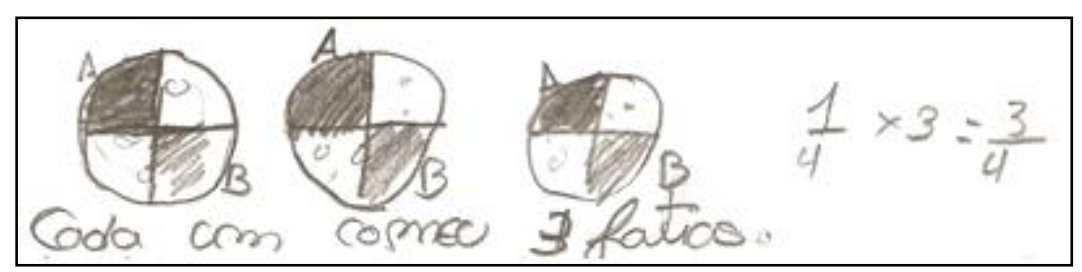

Figura 3 - Resposta de Leonardo à questão 1, da tarefa 1, ficha de trabalho 4

Durante a discussão coletiva da tarefa os alunos explicam a forma como pensaram:

Leonardo: Então nós fizemos 3 pizzas e dividimos...

Professora: Em quantas partes?

Leonardo: Em quatro.

Professora: E agora?

Leonardo: E depois contámos as "pizas" (partes) que cada um comeu.

(Discussão coletiva da questão 1, tarefa 1, ficha de trabalho 4)

Leonardo explica que começaram por fazer as três pizzas e depois dividiram-nas em 4 partes iguais. Embora todos os alunos tenham usado a representação pictórica para resolver esta tarefa, não ficam apenas por esta representação, usando também a representação em fração:

Professora: E depois fizeram mais alguma coisa?

Leonardo: Sim, fizemos contas.

Professora: Que contas fizeram?

Leonardo: Fizemos um sobre quatro...

Professora: Um quarto...

Leonardo: Vezes três é igual a três quartos.

(Discussão coletiva da questão 1 , tarefa 1 , ficha de trabalho 4)

Alguns alunos apresentam a parte que cada um come como produto $\frac{1}{4} \times 3$. Como não trabalharam formalmente a multiplicação entre um número racional e um número inteiro, revelam aqui ter estendido de forma intuitiva o seu conhecimento sobre números inteiros, tendo assim feito uma importante generalização.

Amélia e Leonor, que trabalharam juntas durante toda a unidade de ensino, partem diretamente da figura, assumindo que cada parte representa $\frac{1}{4}$ da pizza e, por consequência, se cada amigo come 3 fatias, isso significa que come $\frac{3}{4}$ de uma pizza. As alunas fazem aqui uma generalização para a adição de frações com o mesmo denominador. 
Leonor: Nós contámos logo. Três do A, três do B... Cada um comia 3 partes, então comia $\frac{3}{4}$.

Professora: Então compreenderam logo que cada fatia correspondia ao tamanho... Turma: $\frac{1}{4}$.

Amélia: Oh professora, mas se cada um comia 3 partes era logo $\frac{3}{4}$.

(Discussão coletiva da questão 1 , tarefa 1 , ficha de trabalho 4)

Nesta situação, envolvendo o significado quociente, os alunos sentem necessidade de se apoiar numa representação informal, a representação pictórica, para resolver as questões propostas. Contudo, sentem que é apropriado usar uma representação formal, a fração, para darem a sua resposta, talvez por começarem a perceber que as representações simbólicas são mais valorizadas em Matemática. Isto pode indiciar que os alunos acham que as representações formais são mais válidas do que as representações informais.

Questão 3. Esta questão pede aos alunos que comparem as partes obtidas nas questões 1 e $2\left(\frac{3}{4} \mathrm{e} \frac{3}{8}\right)$. É igualmente uma situação contextualizada com grandezas contínuas. Esta questão envolve comparação entre frações com numeradores iguais e denominadores diferentes. Vários grupos concluem que, no caso de oito amigos, cada um deles come metade do que comem os do outro grupo, como se vê na Figura 4.

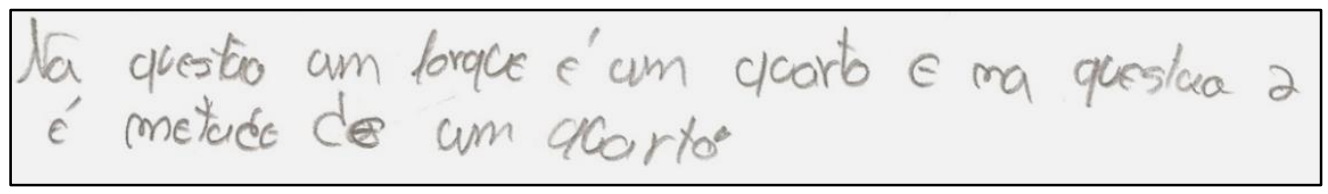

Figura 4- Resposta de Rui à questão 3, tarefa 1, ficha de trabalho 4.

Na discussão desta questão começou-se por estabelecer a relação entre o tamanho da parte que cabe a cada amigo em ambos os casos $\left(\frac{3}{4} \mathrm{e} \frac{3}{8}\right)$ :

Professora: Qual a diferença entre aquilo que cada um come no primeiro caso e no segundo caso? O que é que se alterou?

Amélia: Foi que ficou partido em mais partes.

Professora: E o que é que aconteceu a cada parte?

Alunos: Ficou mais pequenino. Ficou a metade.

Leonor: Pois é, $\frac{3}{8}$ é metade de $\frac{3}{4}$ !

Professora: Quer dizer que cada um passou a comer que parte daquilo que comiam no primeiro caso?

Alunos: A metade.

(Discussão coletiva da questão 3, tarefa 1, ficha de trabalho 4) 
Os que $\frac{3}{8}$ é metade de $\frac{3}{4}$, justificando que cada parte passa a ser metade da anterior. Verifica-se que esta situação apresenta um contexto significativo para os alunos, que os levou a reconhecer facilmente que $\frac{3}{8}$ é metade de $\frac{3}{4}$, o que teria sido provavelmente mais difícil de reconhecer trabalhando apenas em temos abstratos.

Por outro lado, alguns alunos continuam a utilizar os seus conhecimentos informais da situação para fazer a comparação entre as duas frações (Figura 5):

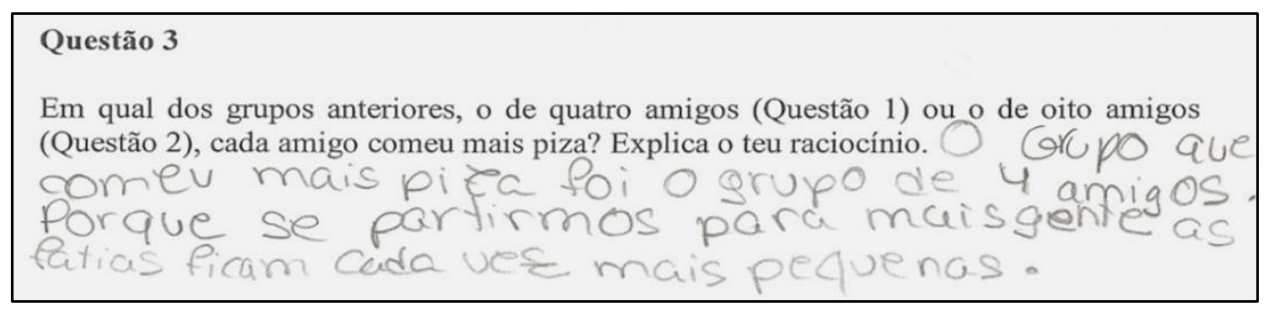

Figura 5 - Resposta de Leonor à questão 3, tarefa 1, ficha de trabalho 4

Professora: Em qual dos grupos anteriores, cada amigo comeu mais pizza?

Nuno: Eu acho que foi na questão 1, porque na 2 tínhamos que dividir as pizzas para 8 pessoas e na 1 só tínhamos 4 pessoas.

André: Pois, tínhamos menos pessoas para distribuir.

Professora: E a quantidade de pizza é sempre a mesma, não é?

Amélia e Leonor: Pois, nós também pensámos assim, só que dissemos que as fatias assim ficavam cada vez mais pequeninas.

Amélia: Podemos concluir que comem o mesmo número de fatias, mas como partimos por menos pessoas (na questão 1) as fatias são maiores.

(Discussão coletiva da questão 3 , tarefa 1 , ficha de trabalho 4)

Neste diálogo, para comparar as frações, os alunos não recorrem a procedimentos formais, que de resto ainda não conhecem. De uma forma exploratória, procuram utilizar o conhecimento prático que têm da partilha, num contexto que lhes é familiar, referindo que $\frac{3}{8}$ é mais pequeno do que $\frac{3}{4}$ porque se distribui a mesma pizza por mais pessoas e, por isso, as fatias são menores, o que constitui uma importante generalização. Fazem assim um raciocínio informal onde atribuem significado aos procedimentos e mostram compreender de uma forma intuitiva a relação existente entre $\frac{3}{4} \mathrm{e} \frac{3}{8}$.

Tarefa. Escreva por ordem crescente os seguintes números: $\frac{1}{4} ; \frac{7}{10} ; 26 \% ; 0,267$

Quadro 3 - Tarefa 3 da ficha de trabalho 4 
Esta tarefa apresenta um contexto puramente matemático. Pede-se aos alunos que ordenem um conjunto de quatro números racionais apresentados em diferentes representações: fração, decimal e percentagem.

Miguel reconhece que $\frac{1}{4}$ é o número mais pequeno (continuando com dificuldade ao dizê-lo verbalmente) mas revela alguma confusão na ordenação de $26 \%$ e 0,267 o que leva Leonor a discordar:

Miguel: $O$ primeiro é 1 de 4.

Professora: Porquê?

Miguel: Porque $\frac{1}{4}$ é igual a 0,25.

Professora: Que é igual a 25\%? OK.

Miguel: A seguir é o 0,267.

Professora: E a seguir?

Miguel: $26 \%$.

Professora: E a seguir?

Miguel: Sete décimos.

Leonor: Eu acho que está mal. $\frac{1}{4}$ está certo, mas o outro dava 26,7\%. (...) Temos de trocar o 0,267 com o $26 \%$.

Professora: Mas também podíamos transformar o $26 \%$ em decimal, como é que ficava?

Leonor: 0,260.

Professora: Então comparando as percentagens ou os decimais chegamos à mesma conclusão. Então e o $\frac{7}{10}$, fica ali porquê?

Aluno: É como se fosse 0,700.

Professora: E em percentagem?

Leonor: $70 \%$.

(Discussão coletiva da tarefa 3, ficha de trabalho 4)

Para comparar os diferentes números, Miguel converte $\frac{1}{4}$ para numeral decimal, usando o procedimento de converter todos os números para a representação decimal. Deste modo, converte as representações dadas para outra representação em que se sente mais confortável. Note-se que o fato de ter dito que 0,267 é menor do que $26 \%$, não se enquadra nas dificuldades descritas na literatura, segundo as quais os alunos têm tendência para considerar 0,267 maior do que 0,26. O aluno poderá ter cometido algum erro na conversão, ou poderá não ter convertido $26 \%$ para decimal.

Leonor por seu lado, refuta a ideia do colega e parece estar já muito à vontade nas conversões entre as várias representações de número racional e também no procedimento formal para comparar números decimais. Converte o numeral decimal para percentagem e percebe que $26,7 \%$ é maior do que $26 \%$. Quando a professora lhe sugere que transforme a 
percentagem em decimal, dá logo a resposta adaptada à necessidade, ou seja, apresenta o resultado com três casas decimais tal como 0,267.

$\mathrm{Na}$ realização desta tarefa os alunos usam apenas as representações formais apresentadas no enunciado, verificando-se uma independência total da representação pictórica que antes usaram profusamente em questões de ordenação de números racionais. No que respeita ao raciocínio, os alunos tendem a usar procedimentos formais, que já dominam com assinalável destreza e que demonstram compreender. É de destacar também a cultura de sala de aula, onde os alunos se sentem à vontade para discordar e corrigir os colegas, verificandose assim um tipo de comunicação dialógica onde a autoridade não se centra unicamente na professora.

\section{Comparação e ordenação de números racionais depois da unidade de ensino}

Apresentamos agora o desempenho de Leonor numa tarefa realizada na segunda entrevista, que teve lugar já depois de concluída a unidade de ensino. Esta tarefa envolve o significado razão e tem um contexto de desporto, conhecido dos alunos.

Tarefa. Num treino de basquetebol dois jogadores estiveram a fazer lançamentos ao cesto e Henrique conseguiu marcar 4 dos 6 lançamentos enquanto o Tomé conseguiu marcar 7 dos 12 lançamentos.

a) Representa sob a forma de fração os lançamentos concretizados por cada um deles.

b) Indica quem deveria ser escolhido para representar a equipa e porquê.

\section{Quadro 4 - Tarefa 1, entrevista final.}

A primeira questão requer a interpretação da informação dada de forma verbal com a passagem dessa informação para a forma de fração, que Leonor faz sem qualquer dificuldade.

Na segunda questão, para comparar $\frac{4}{6} \mathrm{e} \frac{7}{12}$, a aluna utiliza a noção de equivalência de frações e um procedimento para obter frações equivalentes. Refere que, se ambos os jogadores fizessem 12 tentativas, o Henrique concretizaria mais lançamentos. Para ilustrar a sua resposta, transforma $\frac{4}{6}$ numa fração equivalente de denominador 12 (Figura 6). 


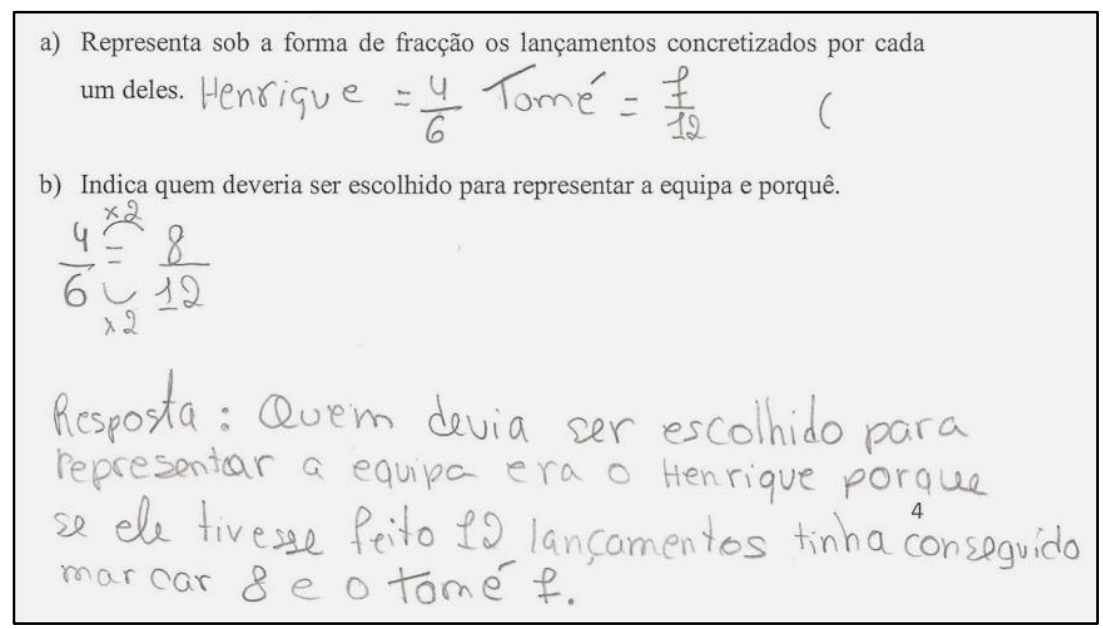

Figura 6 - Resposta de Leonor à tarefa 1, entrevista final

Leonor: Porque ele está mais perto da unidade. E se nós fizéssemos frações equivalentes $6 \times 2=12$ e era igual. $4 \times 2$ é 8 e $6 \times 2$ é 12 .

Professora: E isso quer dizer o quê?

Leonor: Que esta é maior $\left(\frac{8}{12}\right)$ porque são os dois da mesma unidade e 7 é mais pequeno do que 8.

Professora: Isso que dizer que se fizessem os dois 12 lançamentos...

Leonor: Era o Henrique que devia ser escolhido ...

(Entrevista final)

Leonor começa por usar a comparação com a unidade (valor residual). Mas depois passa ao procedimento formal. Justifica o seu raciocínio dizendo que assim ambas as frações estão na mesma unidade. Quer com isso dizer que ambas as frações têm o mesmo denominador, podendo comparar-se apenas os numeradores. O uso do termo incorreto unidade é revelador de uma compreensão intuitiva da possibilidade de se compararem diretamente frações com o mesmo denominador. Neste caso, Leonor já não sente qualquer necessidade de usar representações pictóricas ou decimais mostrando uma boa capacidade para lidar com compreensão com a representação formal em fração.

Assim, após a unidade de ensino, Leonor, mostra facilidade em usar procedimentos formais com compreensão para comparar duas frações, transformando uma delas numa fração equivalente. No entanto, usa também elementos do contexto para justificar as suas respostas, o que mostra que usa os procedimentos com compreensão. O uso de tarefas com contextos familiares e a construção da compreensão dos procedimentos formais tendo por base os procedimentos e representações informais parece ter ajudado a aluna a desenvolver o raciocínio formal com compreensão. 


\section{Conclusão}

Este estudo tem por base uma unidade de ensino em que os alunos trabalham em simultâneo as várias representações dos números racionais, nos diferentes significados, com diferentes tipos de grandezas e em tarefas sobretudo de cunho exploratório. Pretendemos saber em que medida esta unidade proporciona um efetivo desenvolvimento da capacidade para comparar e ordenar números racionais, interessando-nos, sobretudo, a articulação entre representações e processos de raciocínio formais e informais.

A unidade de ensino permitiu a Leonor desenvolver o seu conceito de número racional e adquirir flexibilidade na conversão entre representações. Só tendo trabalhado com frações unitárias no seu percurso escolar anterior, no início do estudo, a aluna conseguia comparar frações em casos muito simples. Além disso, tinha dificuldade na comparação de números representados na forma decimal com um número diferente de casas decimais (assunto que já tinha estudado). Deste modo, mostrava ter algum conhecimento intuitivo, conseguindo lidar com representações simbólicas, mas evidenciando uma compreensão limitada a seu respeito.

O trabalho na unidade de ensino permitiu a Leonor desenvolver a sua compreensão do sistema decimal, deixando de ter dificuldades na comparação nesta representação. No fim da unidade de ensino, revela muito mais à vontade na ordenação de numerais decimais do que no seu início, o que sugere que a decisão de realizar muito cedo um trabalho significativo com numerais decimais surtiu efeito.

No que respeita às frações, Leonor desenvolveu a capacidade de fazer comparações usando procedimentos formais, como a conversão das frações em numerais decimais ou em percentagens (representações que tornam óbvia a comparação), tal como sugerido por Bezuk e Cramer (1989), e o recurso à transformação de frações em frações equivalentes. Em certos casos, a aluna mostra-se capaz de usar processos de raciocínio já com um vincado carater formal, mas apoiadas diretamente nos seus processos de raciocínio informais. Isto sugere que a unidade de ensino promoveu, pelo menos até certo ponto, uma articulação positiva entre processos informais e formais.

Ao longo da unidade de ensino, os alunos podiam optar por trabalhar no âmbito das representações formais, ou, se preferissem, reverter ao uso das representações informais. Leonor foi assim desenvolvendo progressivamente o seu domínio das representações formais de dois modos. Por um lado, isso aconteceu por referência a representações informais (WEBB, BOSWINKEL \& DEKKER, 2008), sobretudo relacionando a representação em 
fração com a pictórica. Por outro lado, isso aconteceu por raciocínios realizados no âmbito das representações formais (procurando estender as propriedades das frações ou explorando as convenções do sistema de representação decimal) e na conversão entre representações formais (ligando, por exemplo, a representação decimal e a percentagem, a representação em fração e a decimal). Deste modo, o seu conhecimento informal foi se ampliando para além do seu campo inicial, constituindo um importante suporte para o conhecimento formal.

A abordagem exploratória, em que os alunos são colocados perante tarefas que têm que resolver recorrendo a processos por eles inventados, revelou-se positiva no desenvolvimento da sua compreensão das relações entre representações e da relação de ordem dos números racionais. A aposta no desenvolvimento da capacidade de usar flexivelmente as diversas representações de números racionais, pondo em pé de igualdade as representações decimal e fracionária, valorizando ainda as representações pictórica e verbal e usando pontualmente as representações em percentagem e na reta numérica, revelou-se apropriada para a aprendizagem da comparação e ordenação, permitindo que os alunos construíssem com compreensão um procedimento natural de ordenação de números racionais.

\section{Agradecimento}

Este trabalho é financiado por fundos nacionais através da FCT - Fundação para a Ciência e Tecnologia no âmbito do Projeto Práticas Profissionais dos Professores de Matemática (contrato PTDC/CPE-CED/098931/2008).

\section{Referências}

BEHR, M. J.; HAREL, G.; POST, T.; LESH, R. Rational number, ratio, and proportion. In: D. A. GROUWS (Ed.). Handbook of research on mathematics teaching and learning. New York, NY: Macmillan, 1992. p. 296-333.

BEZUK, N.; CRAMER, K. Teaching about fractions: What, when, and how? In: P. Trafton (Ed.). New directions for elementary school mathematics. Reston, VA: NCTM, 1989. p. 156-167.

BOGDAN, R.; BIKLEN, S. Investigação qualitativa em educação: uma introdução à teoria e aos métodos. Porto: Porto Editora, 1994.

BRUNER, J. Para uma teoria da educação. Lisboa: Relógio d'Água, 1999.

CHARALAMBOUS, C. Y.; PITTA-PANTAZI, D. Drawing on a theoretical model to study students' understanding of fractions. Educational Studies in Mathematics, Berlim, v. 64, n. 3, p. 293-316, mar. 2007.

COBB, P.; CONFREY, J.; DISESSA, A.; LEHRER, R.; SCHAUBE, L. Designing experiments in educational research. Educational Researcher, Washinton, v. 32, n. 1, p. 9-13, Jan. 2003. 
GOLDIN, G. Perspectives on representation in mathematical learning and problem solving. In: ENGLISH L. (Ed.). International research in mathematics education. 2nd ed. New York, NY: Rutledge, 2008. p. 176-201.

GRAVEMEIJER, K. What makes mathematics so difficult, and what can we do about it? In: SANTOS L., CANAVARRO A. P.; BROCARDO J. (Ed.). Educação matemática: Caminhos e encruzilhadas. Lisboa: APM, 2005. p. 83-101.

LOPES, A. J. O que os nossos alunos podem estar deixando de aprender sobre frações, quando tentamos lhes ensinar frações. BOLEMA, Rio Claro, v. 21, n. 31, p. 1-22. 2008.

LITHNER, J. A research framework for creative and imitative reasoning. Educational Studies in Mathematics, Berlim, v. 67, n.3, p. 255-276, mar. 2008.

MONTEIRO, C.; PINTO, H. Desenvolvendo o sentido do número racional. Lisboa: APM, 2007.

MINISTÉRIO DA EDUCAÇÃO Programa de Matemática do ensino básico. Lisboa: DGIDC, 2007. Disponible en: < http://sitio.dgidc.minedu.pt/matematica/Documents/ProgramaMatematica.pdf > Acesso em 16. Jan.2013.

ORTON, R.; POST, T.; BEHR, M.; CRAMER, K.; HAREL, G.; LESH, R. Logical and psychological aspects of rational number pedagogical reasoning. Hiroshima Journal of Mathematics Education, Hiroshima, v. 3, p. 63-75, mar. 1995.

PONTE, J. P. Gestão curricular em Matemática. In: GTI (Ed.). O professor e o desenvolvimento curricular. Lisboa: APM, 2005. p. 11-34.

PONTE, J. P.; MATA-PEREIRA, J.; HENRIQUES, A. O raciocínio matemático nos alunos do ensino básico e do ensino superior. Praxis Educativa,Ponta Grossa, v. 7, n. 2, p. 355-377, jul/dez. 2012.

PONTE, J. P.; OLIVEIRA, H.; CUNHA, H.; SEGURADO, I. Histórias de investigações matemáticas. Lisboa: IIE, 1998.

POST, T.; BEHR, M.; LESH, R. Research-based observations about children's learning of rational number concepts. Focus on Learning Problems in Mathematics, Framingham, v. 8, n. 1, p. 39-48, Winter Edition. 1986.

POST, T.; CRAMER, K.; BEHR, M.; LESH, R.,; HAREL, G.Curriculum implications of research on the learning, teaching, and assessing of rational number concepts. In: CARPENTER T.; FENNEMA L.; ROMBERG T. (Ed.). Learning, Teaching, and assessing rational number concepts: multiple research perspectives. Hillsdale, NJ: Erlbaum, 1993. p. 327-362.

POST, T.; WACHSMUTH, I.; LESH, R.; BEHR, M. Order and equivalence of rational number: a cognitive analysis. Journal for Research in Mathematics Education, Reston, VA, v. 16, n. 1, p. 18-36, jan. 1985.

VERGNAUD, G. The theory of conceptual fields. Human Development, Basileia, v. 52, n. 2, p. 83-94, abr. 2009.

WEBB, D. C.; BOSWINKEL, N.; DEKKER, T. Beneath the tip of the iceberg. Mathematics Teaching in the Middle School, Reston, VA, v. 14, n. 2, p. 110-113, set. 2008.

Submetido em Junho de 2013. Aprovado em Janeiro de 2014. 